\title{
DESDOBRAMENTOS DA RELAÇÃO ENTRE GESTÃO ESCOLAR E FAMÍLIA DOS EDUCANDOS: UMA METANÁLISE DE ESTUDOS PUBLICADOS ENTRE 2009 E 2019
}

\author{
Valdirene Eliane Bailon Souza ${ }^{2}$ \\ Rita Márcia Andrade Vaz de Mello ${ }^{3}$ \\ Maria de Lourdes Mattos Barreto ${ }^{4}$
}

\section{RESUMO}

Neste artigo, realizamos uma metanálise da produção científica acerca das relações estabelecidas entre gestão escolar e famílias dos educandos no âmbito educacional. Para tanto, utilizamos a base de dados da Web Of Science como fonte para a coleta de informações. Foram catalogados, no período entre 2009 e 2019, 40 artigos relacionados ao tema, os quais foram avaliados por meio do software VOSViewer e da análise de conteúdo. Como resultados, assinalamos a baixa interação da temática entre os autores pesquisados, uma vez que existem discrepâncias de pensamento sobre o processo de gestão escolar e sobre a relação institucional com a família. Nesse

\footnotetext{
${ }^{1}$ Pesquisa Financiada pela Fundação de Amparo à Pesquisa do Estado de Minas Gerais FAPEMING

${ }^{2}$ Mestra em Educação pela Universidade Federal de Viçosa (UFV). Doutoranda na linha de pesquisa Famílias, Políticas Públicas e Desenvolvimento Humano e Social pelo programa de Pós-graduação em Economia Doméstica da UFV. Integrante dos grupos de pesquisa Contextos da infância, adolescência e juventude e suas inter-relações na família e na sociedade, do PPGED / UFV e do grupo de pesquisa Políticas Públicas e a formação de profissionais da Educação (GEPPFOR), do DPE/UFV. https://orcid.org/0000-0002-98554823. Email: vbailondesouza@gmail.com

${ }^{3}$ Doutora em Educação pela Universidade Federal de Minas Gerais (UFMG). Pós-Doutora pela Université Paris Descartes (Sorbonne). Professora e pesquisadora do Programa de Pós-graduação em Economia Doméstica e do Programa de Pós-graduação em Educação da Universidade Federal de Viçosa (UFV). Coordenadora do grupo de pesquisa Políticas Públicas e a formação de profissionais da Educação (GEPPFOR). ORCID: Rita Marcia Andrade Vaz de Mello (0000-0002-7473-9559). Email: ritamarciamello@gmail.com.br

${ }^{4}$ Doutora em Educação pela Universidade Estadual de Campinas (UNICAMP). Professora titular e pesquisadora do Programa de Pós-graduação em Economia Doméstica da Universidade Federal de Viçosa (UFV). Coordenadora do grupo de pesquisa Contextos da infância, adolescência e juventude e suas inter-relações na família e na sociedade. ORCID: https://orcid.org/0000-0001-5575-5900. Email : mlmbarreto@hotmail.com
} 
sentido, observamos que muitas ações são regidas pelos profissionais gestores, que são os profissionais capazes de executar um modelo de educação transformadora da realidade em que atuam, sobretudo no que diz respeito à participação familiar nesse processo de transformação. Contudo, com base nos dados levantados, notamos que a relação gestão escolar e família de educandos não se conectam devido à monopolização da administração escolar, que por sua vez impede uma gestão compartilhada e participativa na escola.

Palavras-chave: Gestão Escolar. Família e Escola. Metanálise.

\section{DEVELOPMENTS IN THE RELATIONSHIP BETWEEN SCHOOL MANAGEMENT AND THE EDUCATIONAL FAMILY: A METANALYSIS OF STUDIES PUBLISHED BETWEEN 2009 AND 2019}

\section{ABSTRACT}

In this article, we conducted a meta-analysis of scientific production about the relationships established between school management and the students' families in the educational field. For this, we used the Web of Science database as a source for collecting information. Between 2009 and 2019, 40 articles related to the topic were cataloged, which were evaluated using the VOSViewer software and content analysis. As a result, we point out the low interaction of the theme among the researched authors, since there are discrepancies in thinking about the school management process and about the institutional relationship with the family. In this sense, we observe that many actions are governed by professional managers, who are professionals capable of implementing a model of education that changes the reality in which they work, especially with regard to family participation in this transformation process. However, based on the data collected, we note that the relationship between school management and the family of students does not connect due to the monopolization of school administration, which in turn prevents shared and participative management at school.

Keywords: School Management. Family and School. Metanalysis. 


\section{AVANCES EN LA RELACIÓN ENTRE LA GESTIÓN ESCOLAR Y LA FAMILIA EDUCATIVA: METANÁLISIS DE ESTUDIOS PUBLICADOS ENTRE 2009 Y 2019}

\section{RESUMEN}

En este artículo realizamos un metaanálisis de producción científica sobre las relaciones que se establecen entre la gestión escolar y las familias de los estudiantes en el ámbito educativo. Para eso, usamos la base de datos de Web Of Science como fuente para recopilar información. Entre 2009 y 2019 se catalogaron 40 artículos relacionados con el tema, los cuales fueron evaluados mediante el software VOSViewer y análisis de contenido. Como resultado, señalamos la baja interacción del tema entre los autores investigados, ya que existen discrepancias en el pensamiento sobre el proceso de gestión escolar y sobre la relación institucional con la familia. En este sentido, observamos que muchas acciones están regidas por gestores profesionales, quienes son profesionales capaces de implementar un modelo de educación que cambie la realidad en la que trabajan, especialmente en lo que respecta a la participación familiar en este proceso de transformación. Sin embargo, a partir de los datos recogidos, observamos que la relación entre la gestión escolar y la familia de los alumnos no se conecta debido a la monopolización de la gestión escolar, que a su vez impide la gestión compartida y participativa en la escuela.

Palabras clave: Gestión Escolar. Familia y Escuela. Metaanálisis.

\section{INTRODUÇÃO}

No presente artigo, realizamos uma metanálise sobre como a gestão escolar é trabalhada com as famílias dos educandos no âmbito educacional. Buscamos, assim, a compreensão de como determinados temas são abordados, sob a análise dos diferentes pesquisadores dessa temática.

Para tanto, inicialmente, efetuamos uma busca na base de dados da Web Of Science, com a utilização do software VOSviewer, especificamente no período entre 2009 e 2019, e obtemos 40 estudos 
que abordavam parcialmente sobre o assunto. Cabe pontuarmos que algumas pesquisas não tinham como foco principal a gestão escolar e a relação institucional com as famílias, mas consideramos importante selecioná-las pelo tema desenvolvido sobre/no referido contexto. Essa constatação foi possibilitada pelo uso do programa supracitado, que auxilia na identificação de palavras-chave e de termos recorrentes nos artigos, conforme proposição pretendida.

Ainda quanto à seleção dos estudos, utilizamos o software (VOSviewer), que é uma ferramenta para construção e visualização de redes bibliométricas. Essas redes podem incluir periódicos, pesquisas ou publicações individuais, sendo construídas a partir de relações de citação, acoplamento bibliográfico, cocitação ou coautoria. Além disso, o VOSviewer oferece a funcionalidade de mineração de texto, o que favorece a construção e visualização de redes de coocorrência de termos importantes extraídos de um corpo literário científico (IBICIT, 2018).

Como metodologia utilizada, realizamos uma revisão sistemática para compilar os dados, por meio da Metanálise, técnica que possibilita reunir, avaliar criticamente e conduzir a síntese de resultados obtidos por múltiplos estudos primários ${ }^{5}$.

Para realizarmos tal trajetória, entendemos que o envolvimento das famílias no ambiente escolar constitui um direito que deve ser legalmente reconhecido como uma necessidade educacional. Nesse sentido, as ações participativas em cada instituição devem ser estabelecidas pelo gestor escolar, sendo essencial o estímulo a essa inserção familiar, para haver a partilha coletiva de informações, compromissos e responsabilidades de cada envolvido (SZYMANZKI, 2011).

É salutar destacarmos que autores como Paro (2011), Libâneo (2013) e Luck (2014) reforçam essa medida, ao sugerirem aos profissionais da gestão uma divisão de poder, que não seja somente relacionada ao domínio ou ao uso de espaços escolares, mas que permita novas ações coletivas, já que a família exerce papel fundamental na escola.

\footnotetext{
${ }^{5}$ Entende-se por estudos primários os artigos científicos que relatam os resultados de pesquisa em primeira mão (GALVÃO; PEREIRA, 2014).
} 
Diante dessa linha reflexiva, percebemos que a relação dos gestores escolares com as famílias dos educandos é uma temática (ainda) sem ênfase científica, pois muitos estudos contemporâneos desconsideram esse relacionamento (LUCK, 2014). Souza (2016) justifica que o enlace não ocorre frequentemente devido à baixa associação, na prática, entre administração e os quesitos pedagógicos e emocionais. Por essa razão, torna-se relevante identificarmos perspectivas e possíveis contradições sob o ponto de vista dos pesquisadores que refletem a esse respeito. Nesse sentido, vale ressaltarmos que a busca literária foi realizada em dados nacionais e internacionais, já que a situação discutida aqui não é exclusiva ao cenário brasileiro.

Após o exposto, descrevemos a estrutura adotada para organização do presente artigo: na primeira parte, efetuamos a contextualização e a exposição do problema, apresentando, também, os dados encontrados; na segunda etapa, são apresentados os resultados e a interpretação dos subsídios obtidos, relacionando-os à literatura do sociólogo Pierre Bourdieu, que suscita aspectos do ambiente escolar; por fim, tecemos as considerações finais sobre o estudo.

\section{COMPREENDENDO A METANÁLISE: localização do problema de pesquisa e coleta de dados}

A Metanálise é uma técnica estatística que combina os resultados de estudos independentes, considerados combináveis, com o propósito de extrair uma conclusão sobre o conjunto da pesquisa. Nesse caso, os contextos histórico, político e social são considerados relevantes para esse tipo de estudo (BICUDO, 2014).

Diante da conjectura atual, consideramos essencial a análise sobre a gestão escolar e seu relacionamento com as famílias dos educandos, uma vez que vêm ocorrendo mudanças veladas e modernizadas nas instituições educacionais, regidas pelo modo imperioso da Constituição.

Neste estudo, realizamos uma revisão sistemática, cujo método segue protocolos específicos científicos, a fim de 
selecionarmos as bases de dados bibliográficos, apresentamos as estratégias de busca empregadas, o processo de seleção dos artigos científicos, os critérios de inclusão e exclusão dos artigos e o processo de análise dos textos eleitos. Explicitamos, ainda, as limitações gerais da pesquisa, bem como demais entraves da própria revisão (BICUDO, 2014).

Segundo Bicudo (2014), toda revisão sistemática efetuada por meio da Metanálise deve(ria) iniciar pela elaboração de uma pergunta-problema a qual pretendemos investigar. Nessa perspectiva, remetemos à questão principal desse artigo: como vem sendo abordada, no contexto científico, a temática da gestão e relacionamento desenvolvido entre o corpo escolar e as famílias dos educandos? Sob esse viés, buscamos pesquisas que tiveram como alvo a investigação desses aspectos, publicadas em um recorte de 10 anos (entre 2009 e 2019).

A seleção dos estudos foi realizada na plataforma da Web of Science, descrevendo-se as palavras-chave no idioma inglês "family", "school management" e "school diretor", que significam, respectivamente, família, gestão escolar e diretor escolar. A partir dessa base, foram localizados 51 estudos, sendo feita a filtragem desses trabalhos para o formato de artigo, o que resultou em 40 - 18 de acesso livre e 22 de acesso restrito (somente resumos). A escolha por trabalhos no formato de artigo advém de sua grande incidência, conferindo resultados a dissertações e teses, por já terem passado pelo crivo de pareceristas de revistas científicas.

Por conseguinte, para explicitarmos os principais sujeitos do estudo, destacamos que o gestor escolar é considerado o profissional capaz de executar um modelo de educação transformadora da realidade em que atua, ou seja, o mesmo possui autonomia para agir de modo que todos envolvidos no contexto escolar participem do processo de transformação, especialmente os familiares dos educandos, estes que são o principal elo com a escola (LIBÂNEO, 2013).

Conforme Szymanzki (2011), a participação das famílias facilita a emancipação do estudante nos âmbitos pessoal e social, pois os familiares são a base de uma boa estrutura comunitária. Por 
isso, a escola deve auxiliar na inculcação de certos princípios, servindo de embasamento e de modelo para relacionamentos sociais futuros.

A análise dos artigos é caracterizada pelo aspecto qualitativo, formado por métodos e técnicas que obrigatoriamente proporcionam um olhar multifacetado sobre a totalidade dos dados selecionados (corpus) no período de coleta. Para tanto, um método muito utilizado é a análise de conteúdo, compreendida como um conjunto de técnicas de pesquisa que visa a busca do(s) sentido(s) de determinado documento (VALA, 2003).

Por fim, a realização de inferências na produção bibliográfica encontrada é a razão de ser da análise de conteúdo, conferindo ao método relevância teórica. Adicionalmente, proporcionamos a comparação entre informações puramente descritivas sobre um tema específico.

\section{A METANÁLISE: interpretação e análise dos resultados da pesquisa}

Nesta fase de análise, primeiramente, verificamos as produções, realizando a leitura desses 40 artigos. Na Tabela 1, a seguir, apresentamos a evolução das pesquisas publicadas por ano, além de sua respectiva variação percentual.

Tabela 1 - Evolução da produção científica sobre Gestão Escolar e Famílias

\begin{tabular}{c|c|c}
\hline Anos de publicação & $\begin{array}{c}\text { Contagem do } \\
\text { registro }\end{array}$ & \% de 40 \\
\hline 2019 & 9 & $22.5 \%$ \\
\hline 2018 & 7 & $17.5 \%$ \\
\hline 2017 & 6 & $15.5 \%$ \\
\hline 2016 & 9 & $22.5 \%$ \\
\hline 2015 & 3 & $7.5 \%$ \\
\hline 2014 & 3 & $7.5 \%$ \\
\hline
\end{tabular}




\begin{tabular}{c|c|c}
\hline 2012 & 2 & $5.0 \%$ \\
\hline 2009 & 1 & $2.5 \%$ \\
\hline Total & $\mathbf{4 0}$ & $\mathbf{1 0 0 \%}$ \\
\hline
\end{tabular}

Fonte: Elaborada pelas autoras (2020).

Conforme Tabela 1, notamos que a produção sobre Gestão Escolar e Famílias foi identificada de forma tímida em 2009, ganhando impulso nos anos posteriores, mesmo que discretamente. Somente nos anos de 2017 e 2018 que ocorreu uma leve inflexão sobre a temática. Nos anos de 2016 e 2019, observamos o ápice e a intensidade das produções, nas quais os autores trabalharam individualmente ou em parcerias com coautores.

Ao serem verificadas as parcerias, percebemos que $70 \%$ do total dos artigos foram produzidos em coautoria, com dois, três ou mais autores, sendo 30\% produções individuais. Há, inclusive, mais publicações em coautorias na área da saúde em comparação à área de ciências sociais e humanas, nas quais prevalecem as publicações individuais.

Outro fato que observamos em relação aos autores é que a maioria dos artigos, correspondente a 31, são de autoria/coautoria do sexo feminino, equivalendo a $78 \%$, enquanto $22 \%$ são do sexo masculino. Isso suscita aspectos atrelados à questão de gênero, já que a área educacional sempre esteve atrelada ao universo feminino.

Recorrendo a parte teórica, Louro (2001) expõe que com a missão de educar as gerações futuras, as mulheres puderam se inserir no mercado de trabalho por meio do magistério. Tal intenção ocorreu principalmente na vida de algumas mulheres de forma imposta, já em relação a outras foi por livre e espontânea vontade, por ambicionarem irem além dos tradicionais espaços sociais e intelectuais atribuídos pela sociedade. No entanto, esse direcionamento para a área educacional, permaneceu cercada por restrições e cuidados para que a sua profissionalização não se chocasse com a sua feminilidade da época.

Felício (2010) em seu estudo sobre a "participação das mulheres na pesquisa" vem pontuar que o crescimento da produção feminina no campo cientifico vem ocorrendo de forma dicotomizada, 
uma vez que as mulheres tendem a se concentrar em determinadas áreas, tais como: Psicologia, Pedagogia, Linguística, Nutrição, Serviço Social, Fonoaudiologia, Economia Doméstica e Enfermagem, os chamados "guetos femininos" ou seja as áreas de "humanas" e "ciências sociais". Essa assertiva do autor nos auxilia a compreendermos o elevado número de autoria feminina nos artigos selecionados, visto que a temática interposta está relacionada justamente a essas áreas de estudo.

As publicações selecionadas foram disponibilizadas por 28 revistas internacionais e nacionais, o que reforça o vasto campo de periódicos que aceitam artigos sobre a temática. Quanto aos principais veículos de divulgação, destacamos cinco principais revistas que abordaram sobre o assunto: "Revista Castilla y León"; "Harvard Educational Review"; "Educação e Pesquisa da USP"; "Revista History of Education \& Children's Literature" e "Revista artciencia.com", todas consideradas importantes fontes de informação da contemporaneidade, da área de humanas, saúde e ciências sociais. As referidas revistas aceitam um campo heterogêneo de dados, com distintos perfis autorais com enfoque na educação escolar, o que demonstra atenção no oferecimento de um espaço rico em vivências, experiências, ensaios ou reflexões teóricas sobre educação como um todo.

Dentre as instituições com maior número de publicações, destacamos: Universidade Complutense de Madrid (Espanha), com três; e Universidade de Cantabria (Espanha), Universidade Estadual da Carolina do Norte (EUA), Universidade de São Paulo (Brasil), Universidade de Bolonha (Itália) e Universidade Católica Portuguesa (Portugal), todas estas com duas publicações em cada. O restante das instituições não apresentadas computou somente uma publicação.

O software VOSviewer contribuiu para a visualização da formação da rede por meio das palavras-chave presente nos artigos. As palavras com maior frequência nos documentos foram: "Gestão Escolar", "Aluno", "Família", "Estudo", "Professor" e "Escola", concernentes à "School Management", "Student", "Family", "Study", "Teacher" e "School" (respectivos termos em inglês). Essas seis palavras tiveram mais de quatro ocorrências nos estudos e, 
consequentemente, foram as que determinaram a temática central das pesquisas.

Em relação aos países que mais contribuíram para o entendimento do tema em questão, citamos Espanha, Estados Unidos e Brasil, conforme demonstrado na Tabela 2.

Tabela 2 - Países com maior número de publicações

\begin{tabular}{l|c}
\hline \multicolumn{1}{c|}{ País } & Número de publicações \\
\hline Espanha & 12 \\
\hline Estados Unidos & 9 \\
\hline Brasil & 6 \\
\hline Itália & 4 \\
\hline Portugal & 3 \\
\hline Austrália & 2 \\
\hline Malásia & 2 \\
\hline Colômbia & 1 \\
\hline Rússia & 1 \\
\hline
\end{tabular}

Fonte: Elaborada pelas autoras, 2020.

A Espanha assume o topo das produções sobre gestão escolar e famílias. O aumento de estudos científicos sobre educação nesse país decorre da importância atribuída pelo governo e pela sociedade à educação como política pública, havendo um investimento substancial na busca da qualidade do Ensino Superior, a partir de ações como, por exemplo, revisão de currículos e incentivo à formação continuada de professores (SOUZA; BATISTA, 2018).

Em segundo lugar, aparecem os Estados Unidos, com uma variedade de colleges e universidades conceituadas, que, além disso, apresentam particularidades para atender às necessidades diversas do país. Desse modo, é notório seu modelo soberano de Educação Superior e de produção científica em relação às demais nações.

No cenário brasileiro, em 2003, foi eleito o Presidente Luís Inácio Lula da Silva, que finalizou seu mandato em 2011. Em seguida, 
foi sucedido pela primeira mulher presidente - Dilma Rousseff (20112016). Essa breve retrospectiva se faz necessária para ressaltarmos algumas pontualidades dessas duas gestões - houve o início da implementação de novas políticas educacionais, incluindo o desenvolvimento de programas de inclusão social. Ocorreu, também, a expansão da Educação Superior, a partir da criação de novas Instituições de Ensino Superior (IES) públicas e privadas, além de políticas que permitiram o acesso à educação aos menos favorecidos (GIANEZINI; ALLEN, 2018). Nesse contexto, ocorreu um avanço em distintas áreas de ensino, abrangendo novas e importantes produções científicas nacionais.

Retornando à caracterização das pesquisas analisadas, constatamos que $85 \%$ dos autores utilizaram a pesquisa de caráter qualitativo e $15 \%$ deram enfoque à pesquisa quali-quantitativa, respectivamente, 34 e 6 no total das produções. Os métodos mais utilizados nesses estudos foram: análise documental, observação participante, revisão bibliográfica, estudo de caso, pesquisas etnográfica, etnometodológica, exploratória, descritiva e pesquisaação. Nesse levantamento, verificamos a pouca quantidade de artigos que realmente detalha a abordagem metodológica escolhida, ou seja, não descreve as especificidades das técnicas empregadas.

Ainda sobre a parte metodológica, presumimos uma dificuldade do(s) pesquisador(es) na definição do método relacionada à falta de instrução (carência de suporte) durante à formação acadêmica. Algumas disciplinas não subsidiam devidamente quanto ao esclarecimento dos métodos disponibilizados para produção científica. Consequentemente, em muitos casos da literatura avaliada, os métodos são citados apenas para cumprir preceitos acadêmicos, ocorrendo esporadicamente à descrição do processo e da literatura a respeito.

As pesquisas de predominância qualitativa ou qualiquantitativa apresentam uma correlação com aportes teóricos da área educacional. Esse entrosamento teórico foi notado somente nos seis estudos brasileiros, que ressaltaram José Carlos Libâneo, Vitor Henrique Paro, Maria Duarte Araújo Castro, Bernadete Gatti e Heloisa Luck, todos pesquisadores da área da gestão escolar, havendo 27 citações desses autores no total de estudos examinados. 
O programa VOSviewer permitiu a delimitação das redes de relações entre todos os estudos, sendo verificada a baixa interação entre os pesquisadores do tema, no que se trata de co-citações e referências semelhantes nos respectivos aportes teóricos. Portanto, evidenciamos uma dispersão a respeito da produção científica sobre os temas "gestão escolar" e "famílias no ambiente escolar".

Assim, após apresentarmos sucintamente os dados que fazem parte da coleta, torna-se imprescindível expor os resultados, os alcances e as implicações trabalhadas sobre o tema. Dessa forma, retratamos, primeiramente, as produções espanholas, conforme demonstrado na Tabela 2.

Os autores espanhóis acreditam que o envolvimento das famílias nas escolas deve ser um direito legalmente reconhecido, constituindo uma demanda social, uma necessidade educacional e um desafio permanente. No entanto, existem poucas oportunidades para as famílias se envolverem com as escolas do país, uma vez que a gestão escolar trabalha a participação principalmente por meio de órgãos colegiados, como as Associações de Pais (Madri e Padres de Alumnos), conhecidos como (AMPAs).

Sobre essa questão, Luck (2014) vem pontuar que essa participação tradicional, atrelada apenas a órgãos colegiados e reuniões para entrega e discussões de notas, tem por objetivo da equipe gestora, fazer com que os familiares e responsáveis legais venham contribuir junto a instituição apenas como uma forma de controle e cobrança do desempenho dos educandos, em vez de estarem associados em um processo de orientação da formação dos filhos e uma participação ativa nas decisões importantes do âmbito escolar.

Os mesmos autores espanhóis concluem que os responsáveis pelos educandos estão dispostos a se comunicarem com a escola e a participarem da educação de seus filhos. Contudo, faltam soluções para aumentar tal participação, carecendo, também, informações que exibam formas de comunicação com administração escolar e corpo docente. Constatamos, assim, que os estudos sumarizam barreiras escolares em termos de envolvimento familiar, mas não abarcam a sugestão de alternativas para a proximidade entre os implicados. 
Outro achado relevante consta nos artigos dos Estados Unidos, corroborando a asserção espanhola: a falta de comunicação entre pais e gestores escolares. Além disso, das poucas identificações advindas desse elo comunicativo, foi notado que os pais geralmente são excluídos do processo de decisão, por ameaçarem de alguma forma o poder decisivo da equipe gestora. Foram elencadas, também, algumas barreiras para a não-participação familiar na escola, tais como: horas excessivas de trabalho dos pais ou responsáveis, horário estrito de trabalho, número de filhos, intensidade do trabalho doméstico, baixa autoestima, entre outras. A maioria dos autores sumarizam que os pais/responsáveis têm informações insuficientes sobre o que devem fazer pela educação de suas crianças e adolescentes, e como isso deve ser realizado.

Sobre esse fato, o Ministério da Educação (MEC), por meio do Instituto Nacional de Estudos e Pesquisas Educacionais Anísio Teixeira (INEP), realizou um estudo nacional sobre a educação no âmbito família e escola. Nesse estudo, puderam constatar que os familiares dos educandos relacionam o comparecimento a escola a fortes preocupações, medos e ansiedades, por acreditarem que o convite está relacionado a problemas disciplinares ou outra gravidade em relação aos filhos (BRASIL, 2018).

Nesse enfoque, os familiares não estão completamente equivocados sobre essa participação, visto que há uma intenção oculta da escola de uma aproximação e colaboração, que é a de promover uma educação e influência para as famílias tidas como "desestruturadas", para que estas possam educar melhor os educandos e estes, por sua vez, possam frequentar a escola sem maiores complicações (SETTON, 2010).

Do mesmo modo, os autores brasileiros reforçam a importância da gestão compartilhada entre as famílias e a equipe escolar, abrangendo, como soluções, formação continuada dos profissionais e políticas públicas específicas para escola e família. Verificamos, ainda, que a participação das famílias não ocorre de forma efetiva, uma vez que a escola também não contribui para essa atuação. Ishida (2016) sugere que as ações realizadas pela escola precisam ser reparadas, com destaque para o fortalecimento do Conselho Escolar e para a maior participação da família na 
elaboração, execução e avaliação do Projeto Político Pedagógico (PPP), a fim de conquistar, de fato, uma gestão participativa.

Em relação aos estudos italianos, estes demonstram uma série de fatores que afetam significativamente o enlace entre gestão escolar e famílias, incluindo questões de gênero, idade, cargo de trabalho dos responsáveis e casamento (na dimensão familiar). Em um desses estudos, Tang (2018) pondera a participação familiar atrelada ao gênero, já que os responsáveis do sexo feminino são mais ativos nas atividades escolares, em comparação aos pais/responsáveis do sexo masculino. O estudo de Rocio (2018) atestou outra questão associada ao gênero, ao perceber que há uma minoria feminina ocupante dos cargos de gestão escolar, não excedendo $30 \%$. Esse autor salienta que existe o poder masculino no controle das escolas, e isso acarreta consequências no âmbito participativo familiar. É válido ressalvarmos que os estudos italianos foram os que mais suscitaram indagações e dúvidas a respeito dos papéis atribuídos à escola e à família, pautados em um modelo ideal que, de alguma forma, acaba perpetuando a iniquidade de gênero.

Por fim, nos estudos italianos, observamos que o principal objetivo dos diretores escolares é atrair e manter os educandos para garantir a sobrevivência das instituições, sem muita aproximação com os familiares. Para atingir esse propósito, os gestores se mostram preocupados em manter serviços dependentes da administração educacional, para serem premiados com base em critérios competitivos institucionais.

Em Portugal, os autores assinalam o contexto educacional como valorizador da participação familiar, para melhoria dos processos educacionais e formação integral dos educandos. Nesses estudos, entendemos que os diretores defendem princípios orientadores e benéficos dessa participação, havendo esforços para promovê-la. Não se pode olvidar que esses profissionais são citados como atores inconscientes nesse processo, pois as escolas contemporâneas ainda seguem normas restritivas e tradicionalistas. Os autores italianos reforçam circunstâncias atuais que submergem o ambiente familiar e a dinâmica escolar, como, por exemplo, o comprometimento, a responsabilidade e o envolvimento dos pais na educação dos filhos. 
Países como Austrália, Malásia, Colômbia e Rússia registraram um a dois artigos publicados, sendo apresentada uma síntese das principais ideias desses estudos. Questões como bullying, questões de gênero, violência, e gestão escolar são permeadas de soluções ou de caminhos para a criação de tais. As pesquisas que expõem o clima organizacional afetado pelas questões acima explicitadas avigoram a necessidade da criação de programas de competência emocional social para os educandos e profissionais em geral, como forma de compreender e evitar possíveis complicações. Nesse seguimento, foram destacadas experiências como o modelo dialógico para resolução de conflitos e criação de comissões mistas para apoio à gestão escolar, formadas por professores, funcionários da instituição, educandos e familiares.

Os autores salientam também que os gestores que atuam em regiões vulneráveis tendem a ter mais dificuldades de efetivarem estratégias com as famílias, para encontrarem soluções aos inúmeros problemas enfrentados. Um percalço citado foi a ausência de estabilidade profissional no quadro de funcionários, justamente por estes não serem efetivos e mudarem de escola todos os anos, não ocorrendo a continuidade do trabalho proposto anteriormente.

A partir da presente análise, notamos que muitos pesquisadores apresentam propostas semelhantes, apesar de haver um olhar diferenciado conforme cada objeto de pesquisa. Nesse sentido, os resultados expressos são seguidos de proposições relacionadas ao maior envolvimento familiar, quando este ainda não integra a rotina das escolas.

Em relação ao processo de informação nas escolas para otimizar a participação familiar, entendemos a complexidade que os gestores, enquanto líderes educacionais, enfrentam para concretizar suas convicções teóricas sobre o compartilhamento de dados educacionais.

As evidências expostas pelas pesquisas analisadas corroboram com a tese de Pierre Bourdieu - onde deveria ser identificados a igualdade de oportunidades, o diálogo democrático e a justiça social, podem ser observadas a reprodução e a legitimação de certas condutas tradicionalistas. Segundo Bourdieu (2001), a autoridade pedagógica, que configura a legitimidade da instituição 
escolar e da ação pedagógica nela exercidas, só pode ser garantida à medida em que o caráter arbitrário e socialmente imposto da cultura escolar não seja hierárquico e voltado aos privilégios de classes.

Nessa perspectiva, é possível dizermos que as ponderações de Bourdieu (2001) sobre o espaço escolar partem da certificação das desigualdades sociais e institucionais. Desta forma, as camadas mais elevadas e prestigiadas dentro das instituições, determinadas em termos de disciplinas, cursos e cargos da gestão escolar, tendem a ser delegadas e ocupadas pelos sujeitos pertencentes aos grupos socialmente dominantes. O sociólogo constata que, por mais que se democratize o acesso à educação por meio da escola pública e gratuita, continuará existindo uma forte correspondência entre as desigualdades sociais, principalmente culturais, entre outras disparidades e hierarquias internas dos sistemas institucionais.

Adicionalmente, atestamos que os recursos externos, como órgãos de segurança e redes de apoio, são acionados pelos gestores somente quando todos os recursos internos estão esgotados, dificultando, assim, as novas possiblidades de amparo no recinto escolar. E isso é recorrente nos cargos de gestão escolar, visto que se observam nos estudos científicos e nas formações continuadas o debate e o esforço para serem implantados os princípios da gestão democrática.

Ainda, é possível notarmos uma cultura escolar dominante. Bourdieu (2001) e Setton (2010) propõem caminhos para uma análise mais crítica do currículo, dos métodos pedagógicos, da avaliação escolar, sobretudo das ações realizadas nas instituições de ensino. Contudo, muitos profissionais da gestão escolar não fazem questão da participação ativa dos familiares dos educandos, visto que essa interação pode ser enxergada como uma ameaça ao que já é imposto como algo absoluto no âmbito institucional.

Sobre as limitações da revisão proposta, utilizamos o software VOSviewer para visualização de redes bibliométricas. Contudo, o programa pouco contribuiu para criação de mapas diante das publicações selecionadas, visto que a temática não foi tratada como foco principal das pesquisas. Mesmo assim, o recurso auxiliou a encontrarmos co-ocorrência(s) de termos. Outro obstáculo a ser pontuado diz respeito ao critério de acoplamento bibliográfico, que 
permitiria a confirmação de determinados grupos por áreas e abordagens similares, ou seja, os autores seriam agrupados de acordo com as referências comumente utilizadas. Percebemos, então, uma escassez de pesquisas na temática proposta, apesar de a falta de informações também constituir um dado, ao apontar a necessidade de pesquisas que compreendam o tema, neste caso, a construção de relações entre equipe gestora e famílias de educandos.

Portanto, as pesquisas que abordam a gestão escolar e a família de educandos apresentam discrepâncias de pensamento sobre esse relacionamento, devido à monopolização da administração escolar, o que impede uma gestão compartilhada e participativa na escola. Mesmo assim, ressalvamos que todos artigos estudados contribuíram, de alguma maneira, para o entendimento do espaço escolar, da conexão família e escola, além de demonstrarem avanços e retrocessos do processo de ensino e aprendizagem e da educação de forma geral.

\section{CONSIDERAÇÕES FINAIS}

Nesse artigo, propomos a Metanálise para investigarmos os estudos nacionais e internacionais que abordam a relação entre gestão escolar e famílias de educandos, publicados no período de 2009 - 2019, como forma de compreender o tratamento dado à referida temática. Sob essa ótica, surgiram reflexões acerca das alternativas propostas para melhorar esse relacionamento e aumentar a participação das famílias no contexto institucional.

Nos 40 artigos selecionados e analisados, notamos que a metodologia mais recorrente é a pesquisa qualitativa, embora haja uma falta de coerência e de equilíbrio entre as ferramentas utilizadas, sendo escassos os trabalhos que realmente detalham o processo metodológico. Quanto aos referenciais teóricos apresentados, constatamos a baixa interação entre a literatura utilizada para discussão do tema, com significativa dispersão na produção científica sobre a relação gestão escolar e família dos educandos.

Paralelamente, tentamos verificar se os estudos selecionados estavam relacionados a escolas públicas ou privadas, visto que poderia ser um dado valioso durante a análise, no que tange aos 
relacionamentos interpostos nessas instituições. No entanto, não foi possível aferir uma apreciação consistente a esse respeito, visto que dos 22 artigos de acesso restrito, somente 6 esclareciam no resumo que a pesquisa se tratava de escolas públicas. Dos 18 de acesso livre, somente 1 estudo na Itália foi direcionado a escola privada, sendo que de um modo geral os artigos não apresentaram nas análises e nos resultados se esse fator interferia ou não nas relações entre escola e família.

Em nenhum dos estudos foi aprofundado, com objetivo principal, o aspecto da convivência específica entre gestores e membros familiares, sendo esse assunto abordado superficialmente apenas como alternativa para resolução de problemas interpostos nas escolas. Com esses dados, acreditamos ser relevante suprir essa lacuna cientifica, por meio de pesquisas que avancem na discussão sobre a relação família/escola e gestão escolar, para que dessa forma os estudos venham propiciar reflexões que contribuam para práticas, ações e implementação de novas possibilidades de intervenção que promovam mudanças significativas para todos envolvidos no emaranhado escolar.

Os estudos de âmbito internacional, como os de Tang (2018) e Rocio (2018), dentre os outros desta análise universal, exibem mais contribuições sob a perspectiva interdisciplinar nas escolas, oferecendo como solução a necessidade de serem institucionalizadas políticas e ações, a fim de otimizar a relação entre familiares e equipe gestora, além de prestar formas de cooperação/ajuda mútua. Em relação aos seis estudos brasileiros, estes pautam-se a participação familiar nas escolas como reforço aos estudos e controle coercitivo dos educandos, como também a contribuição desses responsáveis em eventos e reuniões escolares, entretanto, sem uma cooperação intensa nos contextos decisórios da escola. Ademais, os estudos brasileiros, reforçam a necessidade de reparos e ajustes nas interpelações existentes nas escolas, onde os familiares venham apoiar a instituição e a equipe gestora por diversos olhares, se infiltrando em espaços antes não atingidos ou habitados.

Para compreendermos as relações da cultura escolar, também recorremos aos estudos de Pierre Bourdieu e o mesmo nos sinalizou que em vez de oferecer acesso democrático de uma competência 
cultural específica para todos, o sistema escolar tende a reforçar as distinções de capital cultural de seu público. Nesse sentido, é possível confirmarmos o distanciamento da gestão escolar, não só da família, mas de outros setores pedagógicos, devido à sobrecarga de assuntos administrativos, e, principalmente, à dominação e reprodução de valores velados ao longo dos anos, como explicado pelo sociólogo. Muitas ações são recorrentes na escola, justamente pela incorporação de determinada estrutura social tradicionalista, que persuade o modo de pensar e de agir de todos os envolvidos.

Apesar de termos notado um discreto avanço na produção científica sobre o tema no período avaliado, ainda são requeridas novas pesquisas para a atual demanda escolar, dando atenção a determinadas especificidades. Nos artigos nacionais quanto internacionais, apresentamos fatos do cotidiano escolar que não costumam receber seu devido valor, mas que podem causar problemas graves à escola, a seus integrantes e a sociedade como um todo, haja vista que a família e a escola são as principais instâncias sociais nas quais os alunos (as) estão inseridos. Todavia, as mesmas pesquisas não possuem grande impacto científico, pois a educação ainda não tem sua importância reconhecida, havendo baixo investimento e deferência quanto aos processos relacionais e operacionais concernentes às instituições de ensino.

Esperamos, assim, que novos estudos venham a fomentar um novo olhar para a gestão escolar, propondo investigações que acarretem possíveis modificações em sua organização e em sua postura no que tange ao relacionamento com as famílias dos educandos.

\section{REFERÊNCIAS}

BRASIL. Ministério da Educação. Instituto Nacional de Estudos e Pesquisas Educacionais. Pesquisa nacional qualidade da educação: a escola pública na opinião dos pais. Resumo técnico executivo. Brasília: Ministério da Educação, 2018. 
BICUDO, M. A. V. Metanálise: seu significado para a pesquisa qualitativa. Revista Eletrônica de Educação Matemática, Ed. Temática, v. 9, p. 7-20, 2014.

BOURDIEU, P. Razões práticas: sobre a teoria da ação. 3 ed. Campinas: Papirus, 2001.

FELÍCIO, J. R. D. A política das agências de fomento na promoção da participação das mulheres na pesquisa. In: Encontro nacional de núcleos e grupos de pesquisa pensando gênero e ciências, 2. 2010, Brasília. Brasília: Secretaria Especial de Políticas para as Mulheres, 2010. p. 45-52. Disponível em: http://www.spm.gov.br/publicacoesteste/publicacoes/2010/spm-nucleos-web.pdf. Acesso em: 10 maio. 2020.

GALVÃO, T. F.; PEREIRA, M. G. Revisões sistemáticas da literatura: passos para sua elaboração. Epidemiologia e Serviços de Saúde, v. 23, p. 183-184, 2014.

GIANEZINI, K.; ALLEN, W. R. Notas acerca do desenvolvimento da educação superior nos Estados Unidos e no Brasil: cronologia dos aspectos históricos, sociais e educacionais. Estudios Históricos (RIVERA), v. 10, p. 1-23, 2018.

IBICIT. Tutorial Software VOSviewer. 2018. Disponível em: http://www.larhud.ibict.br/index.php?title=VosViewer. Acesso em: 12 mar. 2020.

ISHIDA, F. L. M. Gestão Democrática: a participação da família na escola. In: I Seminário Internacional de Pesquisa em Políticas Públicas e Desenvolvimento Social. Programa de Pós-graduação em Planejamento e Análise de Políticas Públicas. Franca: UNESP, 2016.

LIBÂNEO, J. C. Organização e gestão da escola: teoria e prática. Goiânia. 6 ed. São Paulo: Ed. Heccus, 2013.

LOURO, G. L. Mulheres na sala de aula. In: PRIORE, Mary Del. História das mulheres no Brasil. São Paulo: Contexto/UNESP, 2001.

LUCK, H. Liderança em gestão escolar. 9 ed. Rio de Janeiro: Ed. Vozes, 2014. 
PARO, V. H. Progressão continuada, supervisão escolar e avaliação externa: implicações para a qualidade do ensino. Revista Brasileira de Educação. v. 16, n. 48, p. 695-716. dez. 2011. Disponível em: http://www.vitorparo.com.br/wp-

content/uploads/2014/06/progressaocontinuadasupervisaoescolare avaliacaoexterna.pdf. Acesso em: 05 fev. 2020.

ROCIO, G. C. Le scuole che si aprono alla comunità ottengono miglioramenti. Rivista History of Education \& Children's Literature, v. 14, n. 3, p. 21-36, 2018.

SETTON, M. da G. J. Uma introdução a Pierre Bourdieu. 2010. Disponível em: http://revistacult.uol.com.br/home/2010/03/umaintroducao-a-pierre-bourdieu/. Acesso em: 21 abr. 2020.

SOUZA, D. B.; BATISTA, N. C. Educação Comparada Brasil-Espanha: Estado da Arte 1990-2014. Revista Ensaio (Rio de Janeiro Online), v. 1, n. 1, p. 1-36, 2018.

SOUZA, V. E. B. O Programa Nacional Escola de Gestores da Educação Básica na Universidade Federal de Viçosa - MG: impasses e perspectivas na visão do Gestor. Dissertação (Mestrado) Universidade Federal de Viçosa, Departamento de Educação. Programa de Pós-Graduação em Educação, 2016.

SZYMANZKI, H. A relação família/escola: desafios e perspectivas. Brasília: Líber Livro, 2011.

TANG, P. H. Lavoro e istruzione a scuola. Rivista di tempi educativi, v. 26, n. 1, p. 6-29, abr. 2018.

VALA, J. A Análise de Conteúdo. In: SILVA, A. S.; PINTO, J. M. (Orgs.). Metodologia das Ciências Sociais. 12 ed. Porto: Edições Afrontamento, 2003. p. 101-128.

Submetido em: Agosto/ 2020.

Aceito em: Abril/ 2021. 